\title{
PENDAMPINGAN PENERAPAN 5S UNTUK PENGELOLAAN BANK SAMPAH YANG EFISIEN DAN EFEKTIF BAGI IBU-IBU PKK WONOKROMO I PLERET BANTUL
}

\author{
Yasrin Zabidi \\ Program Studi Teknik Industri \\ Sekolah Tinggi Teknologi Adisutjipto \\ Jl. Janti Blok R Lanud Adisutjipto Yogyakarta \\ Email : yazma_2000@yahoo.com
}

Received: Januari 2020; Accepted : Februari 2020; Published : Juli 2020

\begin{abstract}
Abstrak
Bank Sampah yang dilakukan oleh ibu-ibu PKK Wonokromo I Pleret, Bantul memberikan manfaat cukup besar. Kondisi ini menjadi peluang bagi ibu-ibu PKK Wonokromo I Pleret untuk menjalankan bank sampah secara rutin. Pengelolaan bank sampah telah memiliki pengurus, sehingga secara manajemen mudah untuk dikembangkan, namun pengelolaan bank sampah yang dilakukan masih belum efektif dan efisiensi. Hal ini terlihat pada proses pemilahan sampah belum berjalan dengan baik, masih banyak sampah yang tercampur dan masih belum tertata rapi, tempat kerja pemilahan yang kurang bersih, terkesan berantakan dan kurang terawat, belum adanya petunjuk pelaksanaan kerja pengelolaan bank sampah. Oleh karena itu perlu dilakukan pendampingan dalam pengelolaan bank sampah yang efisien dan efektif. Metode yang dilakukan terdiri dari 3 langkah tahapan, yaitu tahap identifikasi masalah, tahap pelatihan penerapan konsep 5S (Seiri, Seiton, Seiso, Seiketsu, Shitsuke) dalam pengelolaan bank sampah yang efisien dan efektif, serta tahap studi banding ke bank sampah KSM Salakan Bersemi Potorono yang telah menerapkan 5S. Hasil dari kegiatan ini adalah Ibu-ibu PKK dapat memahami dan menerapkan 5S dalam pengelolaan bank sampah sehingga pengelolaan bank sampah di Wonokromo I Pleret menjadi efisien dan efektif serta mengetahui besarnya manfaat penerapan $5 \mathrm{~s}$ dalam pengelolaan bank sampah.
\end{abstract}

Kata Kunci : Bank Sampah, 5S, 5R

\begin{abstract}
The Waste Bank conducted by PKK Wonokromo I Pleret mothers, Bantul provides considerable benefits. This condition is an opportunity for PKK Wonokromo I Pleret mothers to run a garbage bank regularly. Waste bank management has management, so that management is easy to develop, but the management of waste banks is still not effective and efficient. This can be seen in the process of sorting rubbish that has not gone well, there is still a lot of rubbish that is mixed up and is still not neatly arranged, the workplace of sorting is not clean, seems messy and poorly maintained, there are no guidelines on the implementation of waste bank management work. Therefore it is necessary to provide assistance in managing an efficient and effective waste bank. The method consists of 3 steps, namely the problem identification stage, the training stage of applying the 5S concept (Seiri, Seiton, Seiso, Seiketsu, Shitsuke) in efficient and effective waste bank management, as well as the comparative study stage to the KSM


Salakan Bersemi Potorono waste bank who have implemented 5S. The results of this activity are PKK mothers can understand and apply $5 S$ in waste bank management so that the management of waste banks in Wonokromo I Pleret becomes efficient and effective as well as knowing the benefits of implementing $5 \mathrm{~s}$ in waste bank management.

Keywords: Garbage Bank, 5S, 5R

\section{Latar Belakang Masalah}

Sampah mengandung berbagai bahan beracun seperti logam berat, insektisida, dan sebagainya, sehingga manusia yang kontak langsung dengan sampah dapat berisiko mengalami gangguan pencernaan kronik. Badan Lingkungan Hidup (BLH) DIY mencatat rata-rata jumlah sampah yang dihasilkan oleh warga sebanyak 2,97 1/orang/hari, kota besar sejumlah 2,50 1/orang/hari, kota sedang sebanyak 2,15 1/orang/hari, dan kota kecil pada angka 2,28 1/orang/hari. Konsekuensi dari hal tersebut adalah adanya penumpukan sampah yang mengganggu keindahan serta berpotensi mempengaruhi kesehatan masyarakat [5].

Strategi yang diupayakan dalam usaha pengurangan volume sampah adalah : 1) pengolahan sampah organik dengan penerapan teknologi menjadi sesuatu yang bernilai tambah seperti kompos yang dapat dimanfatkan sebagai pupuk [3], 2) pengolahan sampah plastik dengan penerapan teknologi menjadi bahan bakar minyak sehingga bernilai tambah [8], 3) pengelolaan sampah berbasis masyarakat, yang dalam prosesnya penanganan sampah dilakukan melalui perencanaan dan tata kelola yang dimiliki oleh masyarakat guna meningkatkan kemandirian masyarakat dalam mempertahankan kebersihan lingkungan melalui pengelolaan sampah yang ramah lingkungan. Sistem pengelolaan berbasis masyarakat berasal dari sampah rumah tangga yang terbagi dalam dua jenis, yaitu sampah organik dan anorganik. Sampah organik dikelola menjadi kompos sedangkan sampah anorganik dikelola untuk di daur ulang, digunakan kembali, dan dimusnahkan [1].

Bank sampah merupakan salah satu bentuk MDG (millenium development goals) yang merupakan program yang ingin dicapai sejak tahun 2015 oleh PBB. Tujuan bank sampah adalah untuk membantu menangani pengolahan sampah di Indonesia dan menyadarkan masyarakat akan lingkungan serta merubah paradigma masyarakat mengenai sampah. Bank sampah merupakan salah satu kegiatan social enterprise yang berfokus pada pengelolaan sampah berbasis pemberdayaan masyarakat dimana sampah dikelola dengan optimal sebagai barang yang bernilai guna [6]. Bank sampah merupakan salah satu bentuk partisipasi masyarakat dalam pengolahan sampah. Partisipasi yang diberikan masyarakat berupa kegiatan pemilahan sampah rumah tangga baik berupa sampah organik maupun anorganik yang dilaksanakan oleh masyarakat sendiri [2]. Program pengelolaan sampah mandiri melalui bank sampah, telah menjadi salah satu alternatif solusi bagi pemerintah dan masyarakat dalam pengelolaan sampah yang efektif [9]. Pengolahan sampah melalui bank sampah dapat berjalan efektif dan efesien dengan menerapkan konsep 3R (Reduce, Reuse dan Recycle) [7] dan 5R (Ringkas, Rapi, resik, Rawat, Rajin) [10]. Konsep 5R atau 5S (Seiri, Seiton, Seiso, Seiketsu, Shitsuke) merupakan konsep sikap kerja agar pekerjaan berjalan efektif dan efisien [4].

Bank Sampah yang dilakukan oleh ibu-ibu PKK Wonokromo I Pleret, Bantul memberikan manfaat dan penghasilan yang cukup besar. Kondisi ini menjadi peluang bagi ibu-ibu PKK Wonokromo I Pleret untuk menjalankan dan menggerakkan bank sampah secara rutin. Bank Sampah ini berdiri pada tanggal 7 November 2017. Pengelolaan telah memiliki pengurus, sehingga secara manajemen mudah untuk dikembangkan, namun pengelolaan bank sampah yang dilakukan masih belum efektif dan efisiensi. Hal ini terlihat pada proses pemilahan sampah belum berjalan dengan 
baik, masih banyak sampah yang tercampur dan masih belum tertata rapi, tempat kerja pemilahan yang kurang bersih, terkesan berantakan dan kurang terawat, belum adanya petunjuk pelaksanaan kerja pengelolaan bank sampah.

Berdasarkan uraian diatas, maka dipandang perlu untuk dilakukan pendampingan berupa pelatihan bagi ibu-ibu PKK Wonokoromo I dalam mengelola bank sampah agar efisien dan efektif melalui konsep 5S (Seiri, Seiton, Seiso, Seiketsu, Shitsuke) atau 5 R (Ringkas, Rapi, resik, Rawat, Rajin) )[4], serta studi banding ke bank sampah yang telah menerapkan 5S. Tujuan dari kegiatan ini agar ibu-ibu PKK Wonokoromo I Pleret dapat menerapkan 5S dalam mengelola bank sampah agar efisien dan efektif. Manfaat dari kegiatan ini adalah ibu-ibu PKK Wonokoromo I Pleret memahami konsep 5S dan menerapkan $5 \mathrm{~S}$ dalam pengelolaan bank sampah.

\section{Masalah}

Pemasalahan yang dihadapi oleh ibu-ibu PKK Wonokromo I dalam pengelolaan bank sampah adalah sebagai berikut:

a. Proses pemilahan sampah belum berjalan dengan baik, masih banyak sampah yang tercampur dan masih belum tertata rapi.

b. Tempat kerja pemilahan yang kurang bersih, terkesan berantakan dan kurang terawat.

c. Belum adanya Standart Operational Procedure (SOP) pengelolaan bank sampah

d. Kurangnya pemahaman dan kemampuan Ibu-ibu PKK dalam mengelola bank sampah yang efisien dan efektif

Solusi untuk mengatasi permasalahan tersebut adalah dengan memberikan pendampingan berupa pelatihan bagi ibu-ibu PKK Wonokoromo I dalam mengelola bank sampah agar efisien dan efektif melalui penerapan konsep 5S (Seiri, Seiton, Seiso, Seiketsu, Shitsuke) atau 5 R (Ringkas, Rapi, resik, Rawat, Rajin), serta studi banding ke bank sampah yang telah menerapkan 5S. Oleh karena itu dalam kegiatan Pengabdian pada Masyarakat Semester Gasal T.A. 2019/2020 ini, pengusul melakukan kegiatan pendampingan bagi ibu-ibu PKK Wonokoromo dalam mengelola bank sampah agar efisien dan efektif melalui penerapan konsep 5S (Seiri, Seiton, Seiso, Seiketsu, Shitsuke) atau 5 R (Ringkas, Rapi, resik, Rawat, Rajin).

\section{Metode}

Kegiatan pengabdian pada masyarakat ini dilaksanakan melalui tiga tahap, yaitu:

1) Tahap identifikasi masalah Identifikasi masalah ini dimaksudkan untuk mengetahui permasalahanpermasalahan yang ada dalam bank sampah. Langkah-langkah yang dilakukan dalam tahapan ini adalah:

a. Melakukan survey untuk mengetahui keberadaan bank sampah di wilayah Wonoromo I Pleret, Bantul. Pelaksana PKM melakukan kunjungan kepada pengurus RT untuk mendapatkan data mengenai keberadaan bank sampah di wilayahnya. Berdasarkan kunjungan tersebut diperoleh data bahwa di wilayah Wonokromo I, Pleret terdapat bank sampah yang dikelola oleh ibu-ibu PKK Wonokromo I, Pleret. Alokasi waktu untuk melakukan kegiatan ini adalah 3 jam.

b. Melakukan pertemuan dengan pengurus bank sampah dan pengamatan terhadap pengelolaan bank sampah yang dilakukan oleh ibu-ibu PKK Wonokromo I untuk mengidentifikasi permasalahan-permasalahan yang ada. Alokasi waktu untuk kegiatan ini adalah 7 jam.

2) Tahap Pelatihan 
Setelah dilakukan pertemuan dengan pengurus bank sampah dan pengamatan terhadap pengelolaan bank sampah yang dilakukan oleh ibu-ibu PKK Wonokromo I, maka diperoleh permasalahan dalam pengelolaan bank sampah, berupa : proses pemilahan sampah belum berjalan dengan baik, masih banyak sampah yang tercampur dan masih belum tertata rapi, tempat kerja pemilahan yang kurang bersih, terkesan berantakan dan kurang terawat, belum adanya Standart Operational Procedure (SOP) pengelolaan bank sampah, kurangnya pemahaman dan kemampuan Ibu-ibu PKK dalam mengelola bank sampah yang efisien dan efektif. Untuk mengatasi permasalah tersebut dilakukan pelatihan pengelolaan bank sampah yang efisien dan efektif dengan konsep 5S[10]. Pelatihan ini dilakukan 2 sesi, yaitu:

a. Sesi pertama berupa pemberian teori tentang konsep $5 \mathrm{~S}$ secara umum dan konsep 5S dalam pengelolaan bank sampah. Alokasi waktu untuk kegiatan ini adalah 2 jam

b. Sesi kedua berupa praktek penerapan $5 \mathrm{~S}$ dalam pengelolan bank sampah. Kegiatan ini dilakukan langsung di tempat kerja bank sampah yang diikuti oleh pengurus dan anggota bank sampah. Alokasi waktu untuk kegiatan ini adalah 5 jam. Materi praktek yang diberikan berupa:

a) Seiri (Ringkas) : praktek pemilihan dan menempatkan sampah yang dapat didaur ulang sesuai jenis atau bentuknya, disediakan wadah/keranjang/tong yang untuk menyimpan sampah daur ulang yang telah di pilih sesuai jenisnya.

b) Seiton (rapi), praktek penempatan wadah/keranjang sampah daur ulang telah dipilah dengan rapi, pemberian label pada wadah/keranjang sampah yang dapat didaur ulang.

c) Seiso (resik), praktek pembersihan wadah/keranjang sampah, tempat kerja pemilahan, dan penampungan.

d) Seiketsu (rawat), praktek pembuatan SOP pengelolaan sampah dan jadwal perawatan peralatan yang digunakan.

e) Shitsuke (rajin), praktek membuat jadwal pengumpulan, pemilahan, penyetoran sampah serta melakukan seiri, seiton, seiso secara konsisten.

3) Tahap Studi Banding

Tahap ini dilakukan untuk melengkapi pemahaman ibu-ibu PKK Wonokromo I, Pleret dalam pengelolaan bank sampah yang efisien dan efektif. Studi banding dilaksanakan ke bank sampah KSM Salakan Bersemi Potorono yang telah menerapkan 5S. Kegiatan ini diawali dengan kunjungan pelaksana PKM kepada ketua bank sampah KSM Salakan Bersemi Potorono untuk memperoleh informasi mengenai kesediaan bank sampah KSM Salakan menerima kunjungan studi banding dari ibu-ibu PKK Wonokromo I, Pleret. Alokasi untuk kegiatan ini adalah 2 jam. Setelah mendapat persetujuan, langkah selanjutnya melakukan kegiatan kunjungan studi banding ke bank sampah KSM Salakan Bersemi Potorono dengan alokasi waktu 5 jam.

Target luaran program Pengabdian pada Masyarakat ini agar ibu-ibu PKK Wonokromo I :

1) Mampu memahami dengan konsep 5S (Seiri, Seiton, Seiso, Seiketsu, Shitsuke) atau 5 R Ringkas, Rapi, resik, Rawat, Rajin) dalam pengelolaan bank sampah.

2) Mampu menerapkan $5 \mathrm{~S}$ dalam pengelolaan bank sampah: 
Pendampingan Penerapan 5S untuk Pengelolaan Bank Sampah Yang Efisien dan Efektif ...

a. Seiri (Ringkas) : mampu memilah dan menempatkan sampah yang dapat didaur ulang sesuai jenis atau bentuknya, mampu menyediakan wadah/keranjang/tong yang untuk menyimpan sampah daur ulang yang telah di pilih sesuai jenisnya.

b. Seiton (rapi), mampu menempatan wadah/keranjang sampah daur ulang telah dipilah dengan rapi, memberi label pada wadah/keranjang sampah yang dapat didaur.

c. Seiso (resik), mampu membersihan wadah/keranjang sampah, tempat kerja pemilahan, dan penampungan secara rutin.

d. Seiketsu (rawat), mampu membuat SOP pengelolaan sampah dan jadwal perawatan peralatan yang digunakan.

e. Shitsuke (rajin), mampu membuat jadwal pengumpulan, pemilahan, penyetoran sampah dan semua anggota mampu menjalankan seluruh tahap 5S agar 5S menjadi budaya ibu-ibu PKK dalam mengelola bank sampah.

Luaran dari kegiatan Pengabdian pada Masyarakat ini akan menjadi salah satu topik materi perkuliahan Analisis Produktivitas.

\section{Hasil dan Pembahasan}

Kegiatan pengabdian kepada masyarakat ini ditujukan kepada ibu-ibu PKK Wonokromo I, Wonokromo, Pleret, Bantul yang mengelola bank sampah. Kegiatan pelaksanaan pengabdian kepada masyarakat semester gasal Tahun Akademik 2019/2020 ini diwujudkan dalam pendampingan bagi ibu-ibu PKK Wonokoromo dalam mengelola bank sampah agar efisien dan efektif melalui pelatihan penerapan konsep 5S (Seiri, Seiton, Seiso, Seiketsu, Shitsuke) atau 5 R (Ringkas, Rapi, resik, Rawat, Rajin) dan studi banding ke bank sampah yang telah menerapkan 5S. Hasil dari kegiatan ini adalah sebagai berikut:

1) Tahap identifikasi masalah

Langkah pertama dari program ini adalah melakukan survey lapangan untuk mengetahui keberadaan bank sampah di wilayah Wonoromo I Pleret, Bantul yang dilaksanakan pada tanggal 8 Januari 2020. Pelaksana PKM melakukan kunjungan kepada pengurus RT untuk mendapatkan informasi mengenai keberadaan bank sampah di wilayahnya. Berdasarkan kunjungan tersebut diperoleh informasi bahwa di wilayah Wonokromo I, Pleret terdapat bank sampah yang dikelola oleh ibu-ibu PKK Wonokromo I, Pleret. Selanjutnya pada tanggal 9 Januari 2020 dilakukan pertemuan dengan ibu-ibu PKK Wonokromo I pengelola bank sampah dan pengamatan terhadap pengelolaan bank sampah yang dilakukan oleh ibu-ibu PKK Wonokromo I untuk mengidentifikasi permasalahan-permasalahan yang ada. Berdasarkan hasil pertemuan diskusi dan pengamatan selama 7 jam diperoleh permasalahan sebagai berikut:

a. Proses pemilahan sampah belum berjalan dengan baik, masih banyak sampah yang tercampur dan masih belum tertata rapi.

b. Tempat kerja pemilahan yang kurang bersih, terkesan berantakan dan kurang terawat.

c. Belum adanya Standart Operational Procedure (SOP) pengelolaan bank sampah

d. Kurangnya pemahaman dan kemampuan Ibu-ibu PKK dalam mengelola bank sampah yang efisien dan efektif

2) Tahap Pelatihan

Setelah dilakukan pertemuan dengan pengurus bank sampah dan pengamatan terhadap pengelolaan bank sampah yang dilakukan oleh ibu-ibu PKK Wonokromo 
I, maka diperoleh permasalahan dalam pengelolaan bank sampah, berupa : proses pemilahan sampah belum berjalan dengan baik, masih banyak sampah yang tercampur dan masih belum tertata rapi, tempat kerja pemilahan yang kurang bersih, terkesan berantakan dan kurang terawat, belum adanya Standart Operational Procedure (SOP) pengelolaan bank sampah, kurangnya pemahaman dan kemampuan Ibu-ibu PKK dalam mengelola bank sampah yang efisien dan efektif. Untuk mengatasi permasalah tersebut dilakukan pelatihan pengelolaan bank sampah yang efisien dan efektif dengan konsep 5S. Pelatihan ini dilakukan 2 sesi, yaitu:

a. Sesi pertama dilakukan pada tanggal 20 Januari 2020 jam $08.00-10.00$ (durasi 2 jam) berupa pemberian teori dan diskusi dengan materi berupa: 1) konsep $5 \mathrm{~S}$ secara umum, 2) konsep $5 \mathrm{~S}$ dalam pengelolaan bank sampah dan 3) contoh penerapan $5 \mathrm{~S}$ baik di kehidupan masyarakat maupun dalam pengelolaan bank sampah. Kegiatan ini dihadiri oleh 14 peserta. Luaran yang diperoleh dari kegiatan ini adalah ibu-ibu PKK Wonokromo I, Pleret sebagai pengelola bank sampah dapat menjelaskan dengan baik tentang konsep 5S (Seiri, Seiton, Seiso, Seiketsu, Shitsuke) atau 5 R Ringkas, Rapi, resik, Rawat, Rajin) serta mampu memberikan contoh penerapan $5 \mathrm{~S}$ di lingkungan rumah tangga.

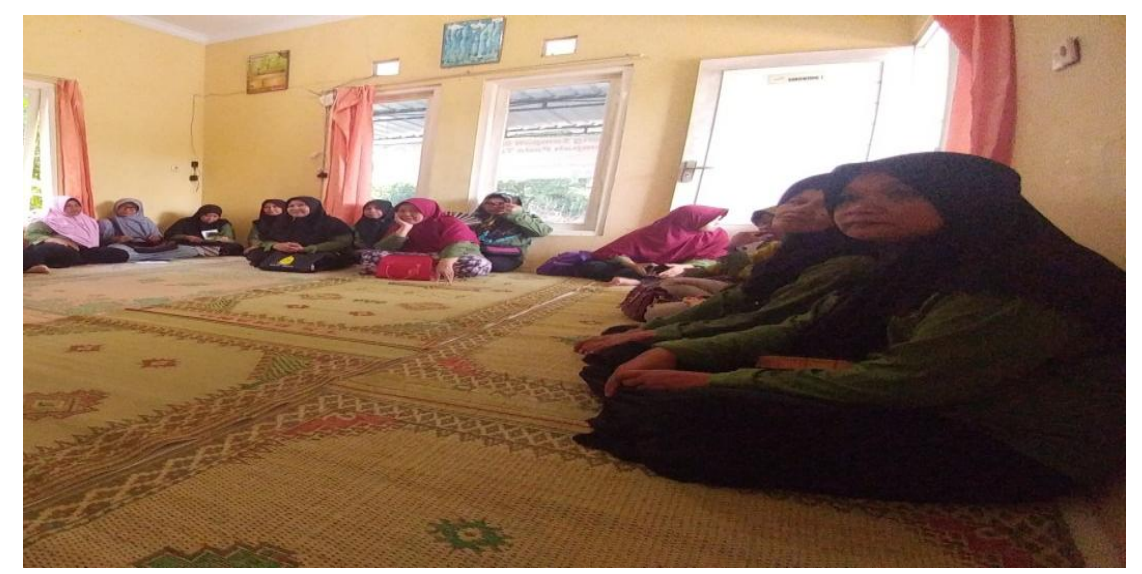

Gambar 1. Peserta Pendampingan Penerapan 5S

b. Sesi kedua dilakukan pada tanggal 20 Januari 2020 jam $10.00-12.00$ dan dilanjutkan jam 13.00 - 16.00 (durasi 5 jam) berupa praktek penerapan 5S dalam pengelolan bank sampah. Kegiatan ini dilakukan langsung di tempat kerja bank sampah Wonokromo I, Pleret yang diikuti oleh 14 peserta (pengurus dan anggota bank sampah). Materi praktek yang diberikan berupa:

a) Praktek Seiri: praktek pemilihan dan menempatkan sampah yang dapat didaur ulang sesuai jenis atau bentuknya, disediakan wadah/keranjang/tong yang untuk menyimpan sampah daur ulang yang telah di pilih sesuai jenisnya.

b) Praktek Seiton : praktek penempatan wadah/keranjang sampah daur ulang telah dipilah dengan rapi, pemberian label pada wadah/keranjang sampah yang dapat didaur ulang.

c) Praktek Seiso praktek pembersihan wadah/keranjang sampah, tempat kerja pemilahan, dan penampungan. 
Pendampingan Penerapan 5S untuk Pengelolaan Bank Sampah Yang Efisien dan Efektif ...

d) Praktek Seiketsu: praktek pembuatan SOP pengelolaan sampah dan jadwal perawatan peralatan yang digunakan.

e) Praktek Shitsuke: praktek membuat jadwal pengumpulan, pemilahan, penyetoran sampah serta melakukan seiri, seiton, seiso secara konsisten.

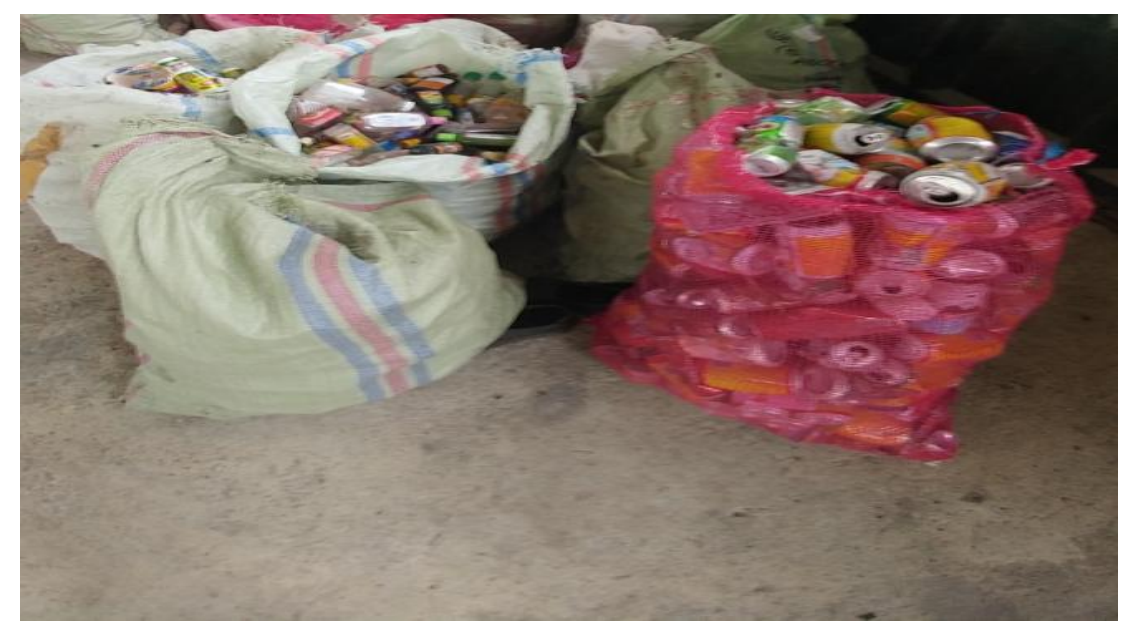

Gambar 2. Pemilahan sampah

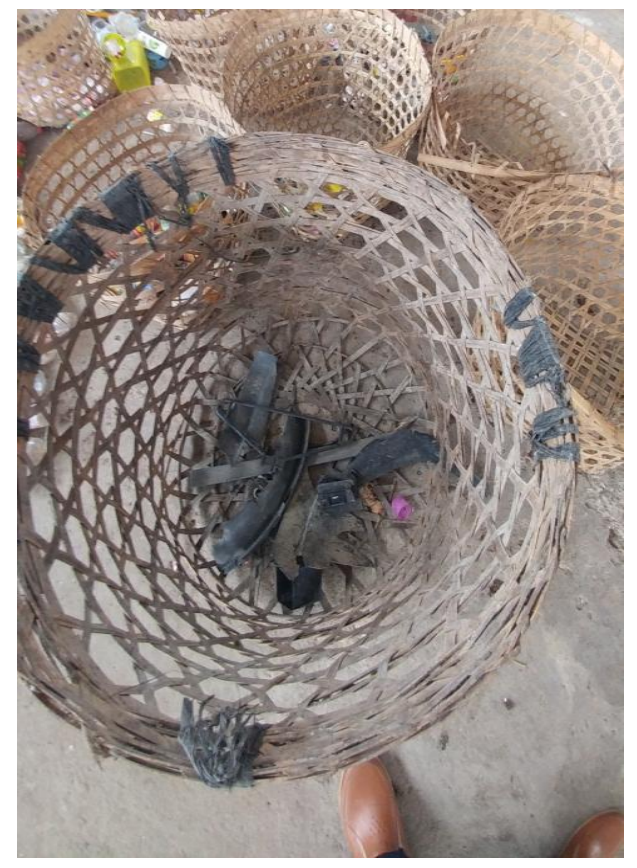

Gambar 3. Keranjang sampah

Luaran yang diperoleh dari kegiatan ini adalah ibu-ibu PKK Wonokromo I, Pleret :

a) Dapat memilah dan menempatkan sampah yang dapat didaur ulang sesuai jenis atau bentuknya.

b) Dapat menyediakan wadah/keranjang/tong yang untuk menyimpan sampah daur ulang yang telah di pilih sesuai jenisnya.

c) Dapat menempatan wadah/keranjang sampah daur ulang telah dipilah dengan rapi, memberi label pada wadah/keranjang sampah yang dapat didaur.

d) Dapat membersihan wadah/keranjang sampah, tempat kerja pemilahan, dan penampungan secara rutin. 
e) Dapat membuat enam SOP pengelolaan sampah (SOP pengumpulan sampah, pemilahan sampah, penyetoran, perbersihan peralatan, pembersihan tempat kerja, pendistribusian)

f) Dapat membuat jadwal perawatan peralatan yang digunakan.

g) Dapat membuat jadwal pengumpulan, pemilahan, penyetoran sampah dan semua anggota mampu menjalankan seluruh tahap $5 \mathrm{~S}$ agar 5S menjadi budaya ibu-ibu PKK dalam mengelola bank sampah

3) Tahap Studi Banding

Studi banding dilaksanakan ke bank sampah KSM Salakan Bersemi Potorono yang telah menerapkan 5S pada tanggal 21 Januari 2020 (08.00 - 13.00) dalam rangka untuk melengkapi pemahaman ibu-ibu PKK Wonokromo I, Pleret dalam pengelolaan bank sampah yang efisien dan efektif dengan konsep 5S. Kegiatan ini diawali dengan penyampaian materi tentang pengelolaan bank sampah oleh Ketua bank sampah KSM Salakan Bersemi Potorono dan dilanjutkan diskusi. Selanjutnya dilakukan peninjauan lapangan di lokasi bank sampah untuk melihat tata letak, penataan peralatan, proses pemilahan, proses pengumpulan, proses pembersihan peralatan dan tempat kerja. Luaran dari kegiatan ini adalah ibu-ibu PKK Wonokormo I, Pleret dapat mengetahui secara nyata bentuk efisiensi dan efektifitas pengelolaan bank sampah yang menerapkan konsep 5S sehingga dengan jelas mengetahui besarnya manfaat dari penerapan $5 \mathrm{~s}$ dalam pengelolaan bank sampah.

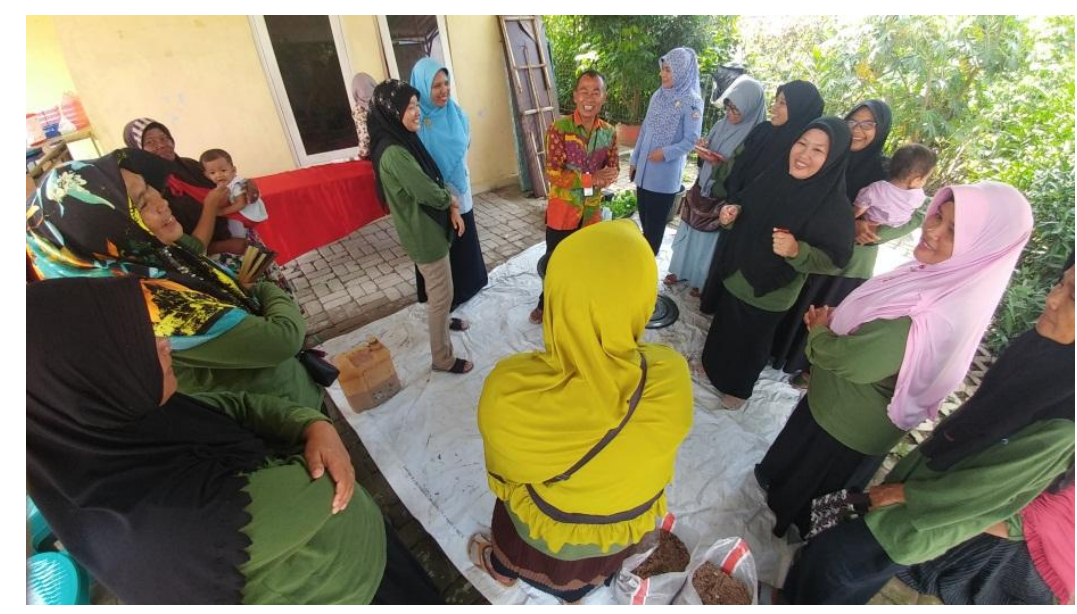

Gambar 4. Studi Banding di Bank Sampah KSM Salakan Bersemi Potorono

4) Evaluasi Kegiatan

Evaluasi kegiatan ini dilakukan untuk mengetahui output/luaran ketercapaian dari kegiatan pengabdian kepada masyarakat ini. Hasil evaluasi kegiatan disajikan dalam tabel 1 .

Tabel 1. Masalah, Target, Ketercapaian

\begin{tabular}{|c|c|c|c|}
\hline Masalah & Solusi & Target & Luaran/Ketercapaian \\
\hline $\begin{array}{l}\text { 1. Proses } \\
\text { pemilahan } \\
\text { sampah } \\
\text { belum } \\
\text { berjalan } \\
\text { dengan baik, } \\
\text { masih }\end{array}$ & $\begin{array}{l}\text { 1. Melakukan pendampingan } \\
\text { berupa pelatihan } \\
\text { penerapan } 5 \mathrm{~S} \text { dalam } \\
\text { pengelolaan bank sampah: } \\
\text { a. Seiri (Ringkas) : } \\
\text { dilakukan pemilihan } \\
\text { dan menempatkan }\end{array}$ & $\begin{array}{l}\text { 1. Mampu } \\
\text { memahami } \\
\text { dengan konsep 5S } \\
\text { (Seiri, Seiton, } \\
\text { Seiso, Seiketsu, } \\
\text { Shitsuke) atau 5 R } \\
\text { Ringkas, Rapi, }\end{array}$ & $\begin{array}{l}\text { 1. Ibu-ibu PKK dapat } \\
\text { memahami dan } \\
\text { menjelaskan dengan } \\
\text { baik tentang konsep } \\
\text { 5S (Seiri, Seiton, } \\
\text { Seiso, Seiketsu, } \\
\text { Shitsuke) atau } 5 \text { R }\end{array}$ \\
\hline
\end{tabular}




\begin{tabular}{|c|c|c|c|}
\hline $\begin{array}{l}\text { banyak } \\
\text { sampah yang } \\
\text { tercampur } \\
\text { dan masih } \\
\text { belum tertata } \\
\text { rapi. } \\
\text { 2. Tempat kerja } \\
\text { pemilahan } \\
\text { yang kurang } \\
\text { bersih, } \\
\text { terkesan } \\
\text { berantakan } \\
\text { dan kurang } \\
\text { terawat. } \\
\text { 3. Belum } \\
\text { adanya } \\
\text { Standart } \\
\text { Operational } \\
\text { Procedure } \\
\text { (SOP) } \\
\text { pengelolaan } \\
\text { bank sampah } \\
\text { Kurangnya } \\
\text { pemahaman } \\
\text { dan } \\
\text { kemampuan } \\
\text { Ibu-ibu PKK } \\
\text { dalam } \\
\text { mengelola } \\
\text { bank sampah } \\
\text { yang efisien } \\
\text { dan efektif }\end{array}$ & 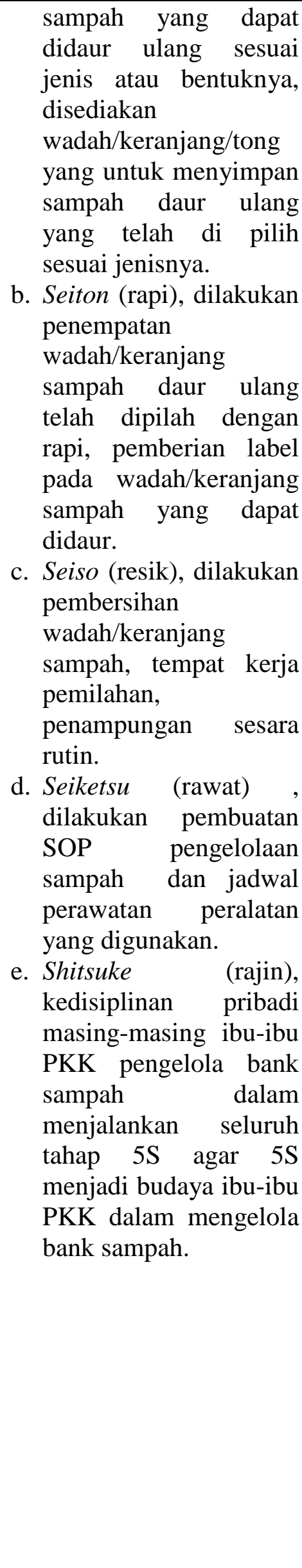 & 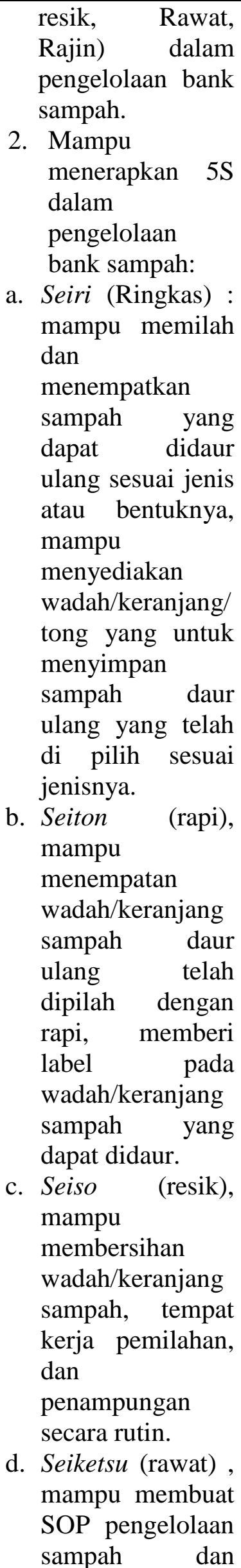 & $\begin{array}{l}\text { 2. Ibu-ibu PKK : } \\
\text { a. Dapat memilah dan } \\
\text { menempatkan sampah } \\
\text { yang dapat didaur } \\
\text { ulang sesuai jenis atau } \\
\text { bentuknya. } \\
\text { b. Dapat menyediakan } \\
\text { wadah/keranjang/tong } \\
\text { yang untuk } \\
\text { menyimpan sampah } \\
\text { daur ulang yang telah } \\
\text { di pilih sesuai } \\
\text { jenisnya. } \\
\text { c. Dapat menempatan } \\
\text { wadah/keranjang } \\
\text { sampah daur ulang } \\
\text { telah dipilah dengan } \\
\text { rapi, memberi label } \\
\text { pada wadah/keranjang } \\
\text { sampah yang dapat } \\
\text { didaur ulang. } \\
\text { d. Dapat membersihan } \\
\text { wadah/keranjang } \\
\text { sampah, tempat kerja } \\
\text { pemilahan, dan } \\
\text { penampungan secara } \\
\text { rutin. } \\
\text { e. Dapat membuat } 6 \\
\text { SOP pengelolaan } \\
\text { sampah dan jadwal } \\
\text { perawatan peralatan } \\
\text { yang digunakan. } \\
\text { f. Dapat membuat } \\
\text { jadwal pengumpulan, } \\
\text { pemilahan, sank } \\
\text { penyetoran sampah } \\
\text { dan semua anggota } \\
\text { mampu menjalankan } \\
\text { seluruh tahap } 5 \mathrm{~S} \text { agar } \\
\text { 5S menjadi budaya } \\
\text { ibu-ibu PKK dalam } \\
\text { mengelola } \\
\text { sampah ba }\end{array}$ \\
\hline
\end{tabular}


2. Melakukan studi banding ke bank sampah KSM Salakan Bersemi Potorono yang telah menerapkan $5 \mathrm{~S}$

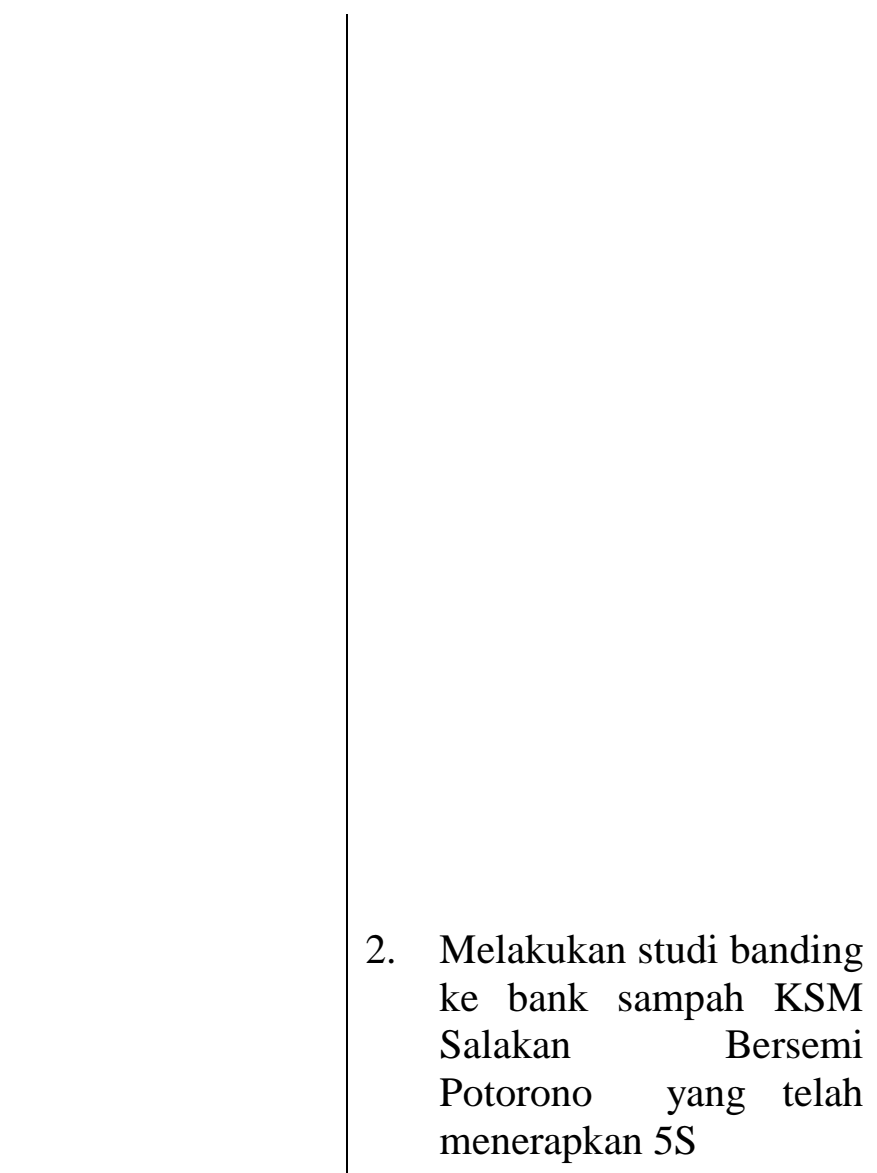

\section{Kesimpulan}

Berdasarkan pelaksanaan kegiatan pengabdian kepada masyarakat berupa pendampingan penerapan $5 \mathrm{~S}$ untuk pengelolaan bank smapah yang efisien dan efektif bagi ibu-ibu PKK Wonokromo I, Pleret Bantul diperoleh kesimpulan sebagai berikut:

1) Kegiatan pendampingan yang dilakukan berupa pelatihan bagi ibu-ibu PKK Wonokoromo I dalam mengelola bank sampah agar efisien dan efektif melalui penerapan konsep 5S (Seiri, Seiton, Seiso, Seiketsu, Shitsuke), serta studi banding ke bank sampah KSM Salakan Bersemi Potorono yang telah menerapkan 5S.

2) Luaran dari kegiatan pelatihan bagi ibu-ibu PKK Wonokoromo I dalam mengelola bank sampah agar efisien dan efektif melalui penerapan konsep 5S adalah : Ibu-ibu PKK dapat memahami dan menjelaskan dengan baik tentang konsep 5S, dapat memilah dan menempatkan sampah yang dapat didaur ulang sesuai jenis atau bentuknya, dapat menyediakan wadah/keranjang/tong yang untuk menyimpan sampah daur ulang yang telah di pilih sesuai jenisnya, dapat menempatan wadah/keranjang sampah daur ulang telah dipilah dengan rapi, memberi label pada wadah/keranjang sampah yang dapat didaur ulang, dapat membersihan wadah/keranjang sampah, tempat kerja pemilahan, dan penampungan secara rutin, dapat membuat 6 SOP pengelolaan sampah dan jadwal perawatan peralatan yang 
digunakan, serta dapat membuat jadwal pengumpulan, pemilahan, penyetoran sampah dan semua anggota mampu menjalankan seluruh tahap $5 \mathrm{~S}$ agar $5 \mathrm{~S}$ menjadi budaya ibu-ibu PKK dalam mengelola bank sampah

3) Luaran dari kegiatan studi banding ke bank sampah KSM Salakan Bersemi Potorono yang telah menerapkan 5S adalah ibu-ibu PKK Wonokormo I, Pleret dapat mengetahui secara nyata bentuk efisiensi dan efektifitas pengelolaan bank sampah yang menerapkan konsep 5S sehingga dengan jelas mengetahui besarnya manfaat dari penerapan 5 s dalam pengelolaan bank sampah

4) Kegiatan ini berjalan dengan baik dan mendapat respon yang positif dari ibu-ibu PKK Wonokromo I, Pleret Bantul.

\section{Daftar Pustaka}

[1] Asteria, D., \& Heruman, H. (2016). Bank sampah sebagai alternatif strategi pengelolaan sampah berbasis masyarakat di Tasikmalaya (Bank Sampah (Waste Banks) as an alternative of community-based waste management strategy in Tasikmalaya). Jurnal manusia dan lingkungan, 23(1), 136-141.

[2] Bachtiar, H. (2015). Pengembangan bank sampah sebagai bentuk partisipasi masyarakat dalam pengelolaan sampah (studi pada koperasi bank sampah Malang). Jurnal Administrasi Publik, 3(1), 128-133

[3] Indrawati, R., Hindarti, F., \& Puspitasari, A. (2020). Diseminasi Teknologi Pengolahan Sampah Terpadu di Kabupaten Purworejo. KACANEGARA Jurnal Pengabdian pada Masyarakat, 3(1), 81-90.

[4] Osada, Takashi. 2004. Sikap Kerja 5S. Jakarta : PPM.

[5] Rohmawati, D., 2015, Kewiralembagaan dalam Pengelolaan Sampah Berbasis Masyarakat di Bank Sampah Gemah Ripah, Badegan, Bantul, Jurnal Studi Pemuda, 4 (2)

[6] Setyaningrum, I., 2015, Karakteristik Pengelolaan Sampah Oleh Masyarakat Melalui Bank Sampah, Jurnal Teknik PWK,4 (2),

[7] Shentika, P. A. (2016). Pengelolaan Bank Sampah di Kota Probolinggo. Jurnal Ekonomi dan Studi Pembangunan, 8(1), 92-100.

[8] Styana, U. I. F., Hindarti, F., Ardito, M. N., \& Cahyono, M. S. (2019). Penerapan Teknologi Pengolahan Sampah Plastik menjadi Bahan Bakar Minyak untuk Mengatasi Masalah Sampah di Kota Bandung. KACANEGARA Jurnal Pengabdian pada Masyarakat, 2(1), 1-6

[9] Suryani, A. S. (2014). Peran bank sampah dalam efektivitas pengelolaan sampah (studi kasus bank sampah Malang). Jurnal Aspirasi, 5(1), 71-84.

[10] Theresia, 2018, Pelatihan dan Pendampingan 5R Pengelolaan Lingkungan Kerja Bank Sampah TPS3R Vipamas Kelurahan Bambu Apus, Technopex-2018, ISSN 2654-489X (314-319) 
Yasrin Zabidi 